\title{
The Desmosome
}

\author{
Emmanuella Delva, Dana K. Tucker, and Andrew P. Kowalczyk \\ Departments of Cell Biology and Dermatology, Emory University School of Medicine, Atlanta, Georgia 30322 \\ Correspondence: akowalc@emory.edu
}

Desmosomes are intercellular junctions that tether intermediate filaments to the plasma membrane. Desmogleins and desmocollins, members of the cadherin superfamily, mediate adhesion at desmosomes. Cytoplasmic components of the desmosome associate with the desmosomal cadherin tails through a series of protein interactions, which serve to recruit intermediate filaments to sites of desmosome assembly. These desmosomal plaque components include plakoglobin and the plakophilins, members of the armadillo gene family. Linkage to the cytoskeleton is mediated by the intermediate filament binding protein, desmoplakin, which associates with both plakoglobin and plakophilins. Although desmosomes are critical for maintaining stable cell-cell adhesion, emerging evidence indicates that they are also dynamic structures that contribute to cellular processes beyond that of cell adhesion. This article outlines the structure and function of the major desmosomal proteins, and explores the contributions of this protein complex to tissue architecture and morphogenesis.

$\mathrm{T}^{\mathrm{h}}$ he desmosome is an adhesive intercellular junction that is crucial to tissues that experience mechanical stress, such as the myocardium, bladder, gastrointestinal mucosa, and skin (Getsios et al. 2004b; Holthofer et al. 2007). The desmosome was first observed in the spinous layer of epidermis by the Italian pathologist Giulio Bizzozero (1846-1901). Bizzozero's observations of these small dense nodules, subsequently named "nodes of Bizzozero," led him to the insightful interpretation of these structures as adhesive cell-cell contact points. The term desmosome was later coined by Josef Schaffer in 1920 and is derived from the Greek words "desmo," meaning bond or fastening, and "soma," meaning body (Wells 2005; Calkins and Setzer 2007). The introduction of electron microscopy yielded a series of advances by Porter, Odland, and Kelly in the 1950s and 1960s, which revealed desmosome organization at the ultrastructural level. These studies and others indicated that the desmosome can be divided into three morphologically identifiable zones: the extracellular core region (desmoglea), the outer dense plaque (ODP), and the inner dense plaque (IDP) (Fig. 1A) (Kowalczyk et al. 1994; Schmidt et al. 1994; Green and Jones 1996; North et al. 1999; Garrod and Chidgey 2008).

In the mid 1970s, Skerrow and Matoltsy (Skerrow and Matoltsy 1974a; Skerrow and Matoltsy 1974b) advanced the field by isolating desmosomes using biochemical approaches (Bass-Zubek and Green 2007).

Editors: W. James Nelson and Elaine Fuchs

Additional Perspectives on Cell Junctions available at www.cshperspectives.org

Copyright (C) 2009 Cold Spring Harbor Laboratory Press; all rights reserved; doi: 10.1101/cshperspect.a002543

Cite this article as Cold Spring Harb Perspect Biol 2009;1:a002543 
E. Delva, D.K. Tucker, and A.P. Kowalczyk

A

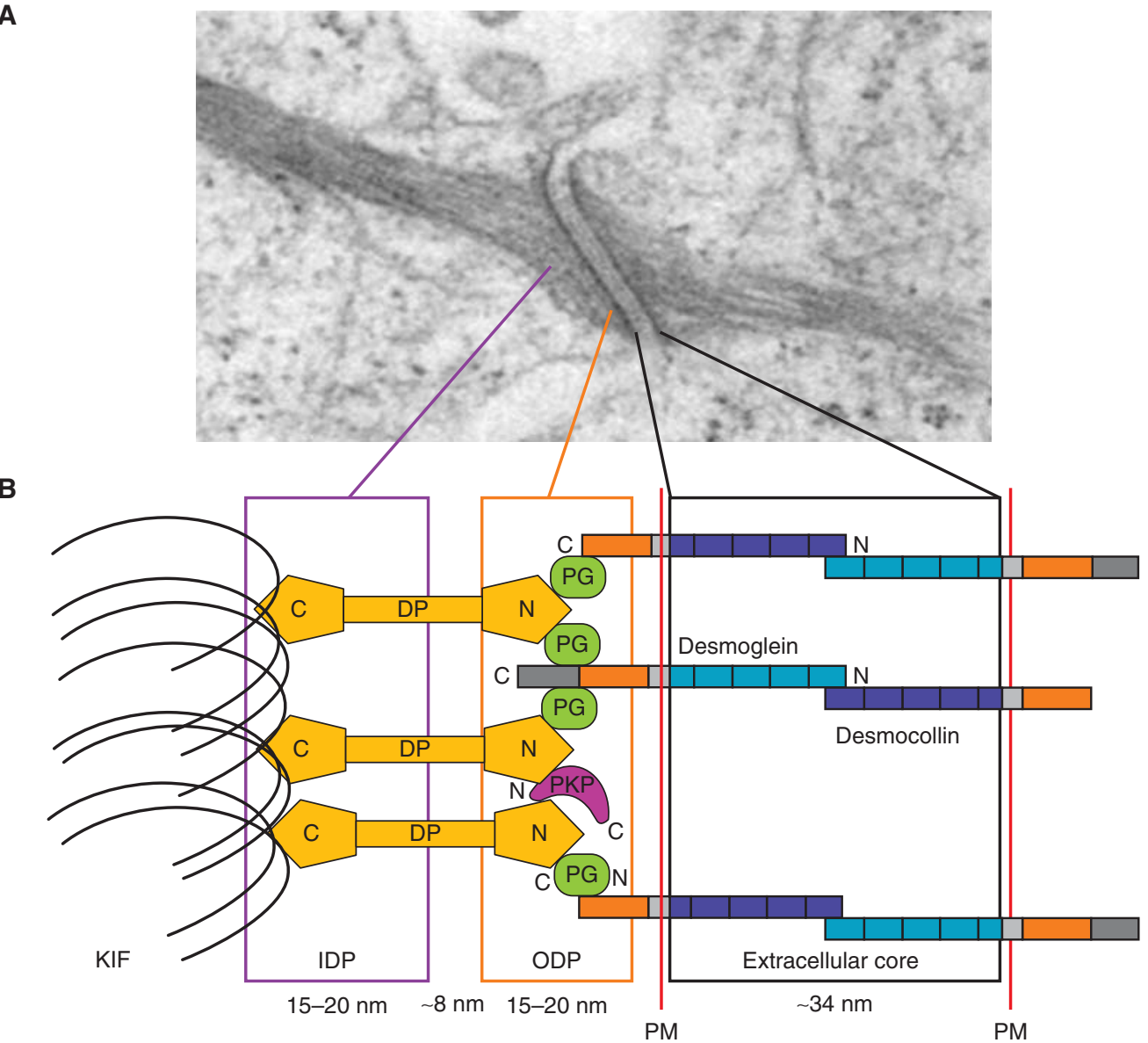

Figure 1. A model for the structure of desmosomes. (A) Electron micrograph of a desmosome. (B) Schematic of desmosomal proteins and relative distance from the plasma membrane (PM). The desmosomal cadherins, the desmogleins and desmocollins, extend into extracellular core and outer dense plaque (ODP) to establish contact and adhere to neighboring cells in a $\mathrm{Ca}^{2+}$-dependent manner. The cadherin cytoplasmic tails associate linker proteins, plakoglobin (PG), the plakophilins (PKP), and desmoplakin (DP). DP binds to keratin intermediate filaments (KIF) within the inner dense plaque (IDP), serving to tether the intermediate filaments to the plasma membrane. (Adapted with permission from Kottke et al. 2006.)

These landmark studies provided a foundation for the Franke and Steinberg laboratories to characterize the transmembrane glycoproteins and cytoplasmic plaque proteins that linked the structure to the intermediate filament cytoskeleton, and to develop immunological tools for localizing specific components (Franke et al. 1981; Kapprell et al. 1985; Steinberg et al. 1987). Collectively, these and other studies shaped our current view of how desmosomal components are organized.
The transmembrane glycoproteins, termed desmogleins and desmocollins (Garrod and Chidgey 2008), represent separate subfamilies of the cadherin superfamily of calcium dependent adhesion molecules. The extracellular domains of the desmogleins and desmocollins mediate adhesion, whereas the cytoplasmic tails of these cadherins associate with the desmosomal plaque proteins. The outer dense plaque consists of the cytoplasmic tails of the desmosomal cadherins, which bind to 
The Desmosome

members of the armadillo and plakin family of linker proteins (Kowalczyk et al. 1994; Getsios et al. 2004b; Garrod and Chidgey 2008). Plakoglobin, a member of the armadillo family, binds directly to the cytoplasmic tails of both the desmogleins and the desmocollins (Wahl et al. 1996; Witcher et al. 1996). Desmoplakin, a member of the plakin family, interacts with both plakoglobin and another subgroup of armadillo family proteins, the plakophilins (Cowin and Burke 1996). Finally, the interaction between desmoplakin and the keratin filaments forms the inner dense plaque, tethering the cytoskeletal network to the adhesion complex (Fig. 1B) (Kowalczyk et al. 1994; Getsios et al. 2004b; Garrod and Chidgey 2008).

The following sections of this article describe the structural and functional characteristics of the major desmosomal proteins. In addition, we discuss differences in tissue expression patterns of desmosomal proteins and the role of desmosomes in human disease. A comprehensive review of additional proteins found to regulate or associate with desmosomes is provided elsewhere (Holthofer et al. 2007) and discussion of desmosome dynamics is provided in Green et al. 2009.

\section{THE DESMOSOMAL CADHERINS}

\section{Desmogleins and Desmocollins: Structure and Function}

Desmogleins (Dsgs) and desmocollins (Dscs) are the two types of desmosomal cadherins (Nollet et al. 2000). In humans, there are three isoforms of desmocollins (Dsc 1-3) and four isoforms of desmogleins (Dsg 1-4) (Green and Simpson 2007). All three desmocollin gene products undergo alternative splicing, resulting in the generation of the Dsc " $a$ " form and a shorter Dsc " $b$ " form of the proteins, which differ in the length of their respective carboxy-terminal domains (Fig. 2) (Collins et al. 1991; Parker et al. 1991). Evolutionarily and structurally, the desmocollin genes are more closely related to the classical cadherins (i.e., E- and N-cadherin) than they are to the desmogleins (Kljuic et al. 2004).

The desmogleins and desmocollins both contain four extracellular cadherin homology repeats and a fifth domain termed the extracellular anchor (Fig. 2). Cadherin repeats are approximately 110 amino acids each and are separated by calcium binding motifs. Extracellular calcium supports cadherin mediated

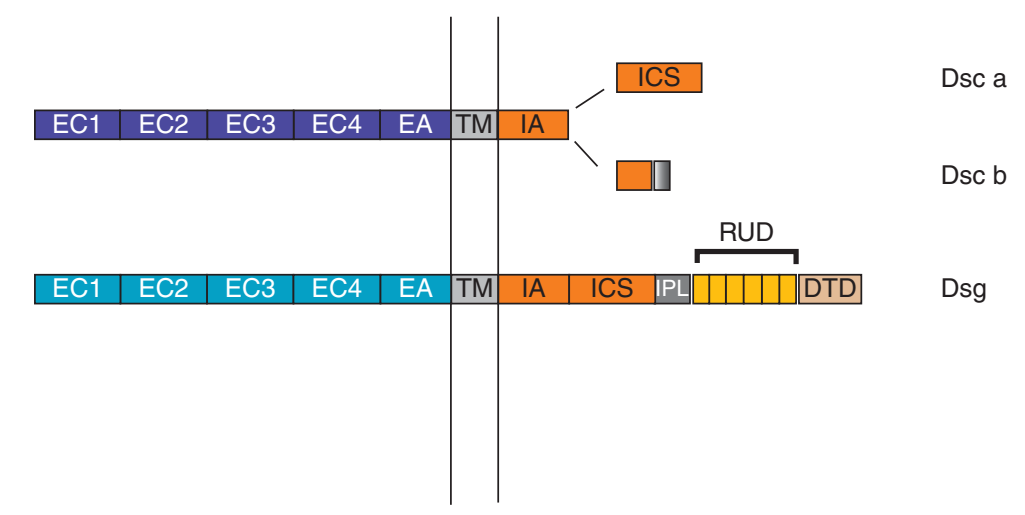

Figure 2. Domains of the desmosomal cadherins. Desmogleins (Dsg) and desmocollins (Dsc) contain four highly conserved extracellular (EC) domains, a more variable extracellular anchor (EA), a single transmembrane domain (TM), and an intracellular anchor (IA), which is followed by additional cytoplasmic domains. Desmocollin "a" isoforms and desmogleins contain an intracellular cadherin-like sequence (ICS) that binds plakoglobin. Desmogleins contain the additional intracellular proline-rich linker (IPL), a variable number of repeat unit domains (RUD), and a desmoglein terminal domain (DTD). The numbers of RUDs contained in each desmoglein isoform are as follows: Dsg 1, 5 repeats; Dsg 2, 6 repeats; Dsg 3, 2 repeats; and Dsg 4, 3 repeats. 
adhesion by allowing the cadherin extracellular domain to assume a rigidified and functional conformation (Pokutta and Weis 2007).

A single pass transmembrane domain is followed by an intracellular anchor (IA) located at the cytoplasmic face of the plasma membrane (Kowalczyk et al. 1999a; Green and Simpson 2007; Holthofer et al. 2007). Desmogleins and the longer Dsc "a" form contain an intracellular cadherin-like sequence (ICS), which binds plakoglobin (Mathur et al. 1994; Troyanovsky et al. 1994; Roh and Stanley 1995). The desmogleins also harbor other unique motifs that are specific to this subfamily of the cadherins, including an intracellular proline-rich linker (IPL) domain, a variable number of repeat unit domain (RUD), and a glycine-rich desmoglein terminal domain (DTD) (Fig. 2) (Holthofer et al. 2007; Garrod and Chidgey 2008).

Desmosomes show $\mathrm{Ca}^{2+}$-dependent assembly and adhesion, although the precise mechanisms of desmosomal cadherin adhesion and specificity are not fully understood. Classical cadherins typically show homophilic interactions, which support cell-cell adhesion and tissue patterning. Most studies to date suggest that both desmocollins and desmogleins are required for strong cell-cell interactions (Marcozzi et al. 1998; Tselepis et al. 1998; Getsios et al. 2004a). However, it remains unclear whether homophilic or heterophilic interactions are primarily responsible for desmosome adhesion. Heterophilic interactions between Dsg2 and Dscla were observed in human fibrosarcoma cells (HT-1080) (Chitaev and Troyanovsky 1997) and between Dsg2 and Dsc2 using recombinant polypeptides encompassing the first two extracellular domains of the proteins (Syed et al. 2002).

Other studies using atomic force microscopy suggest homophilic interactions mediated by the desmogleins (Waschke et al. 2005; Heupel et al. 2008). Additional studies are required to understand precisely how these cadherins associate and assemble into the highly organized adhesive interface observed in mature desmosomes (Al-Amoudi and Frangakis 2008).
Role of Desmosomal Cadherins in Epithelial Differentiation

The desmosomal cadherins show complex developmental and differentiation patterns of expression (Holthofer et al. 2007). Dsg2 and Dsc2 are expressed widely and in all desmosome bearing tissues, whereas the other desmosomal cadherins are predominantly expressed in stratifying epithelia. In the epidermis, all seven desmosomal cadherins are present. Furthermore, these genes are differentially expressed as keratinocytes and undergo terminal differentiation (Fig. 3) (Kottke et al. 2006; Holthofer et al. 2007). Dsg2 and Dsg3 are mainly distributed throughout the lower layers of the epidermis, whereas Dsg1 is expressed at higher levels in the upper layers. Dsg4 is primarily expressed in the hair follicle and in the granular layer. With respect to the desmocollins, Dsc2 and Dsc3 are present in the basal and spinous layers, whereas Dsc1 is expressed in the granular layer. The differential expression pattern of the desmosomal cadherins implies that desmosomes within different tissues are biochemically, and presumably functionally, distinct.

The precise role for the tissue-specific expression patterns of desmosomal cadherins is not fully understood, but manipulation of desmosomal cadherin expression suggests that tight regulation of their expression pattern is critical to tissue homeostasis. Misexpression of Dsg3 using the keratin 1 promoter to drive expression in the suprabasal epidermal layers in transgenic mice resulted in epidermal hyperproliferation and abnormal differentiation (Merritt et al. 2002). Furthermore, expressing Dsg3 in the upper layers of the epidermis using the involucrin promoter resulted in an even more severe phenotype, including a resemblance to oral mucosa, a reduction in epidermal barrier function, and early postnatal lethality because of extensive water loss (Elias et al. 2001). More recently, Dsg2 misexpression in the differentiated layers of the epidermis was found to cause hyperproliferation and susceptibility to chemically induced carcinogenesis (Brennan et al. 2007). Gene ablation studies have also revealed key roles for desmosomal 
The Desmosome

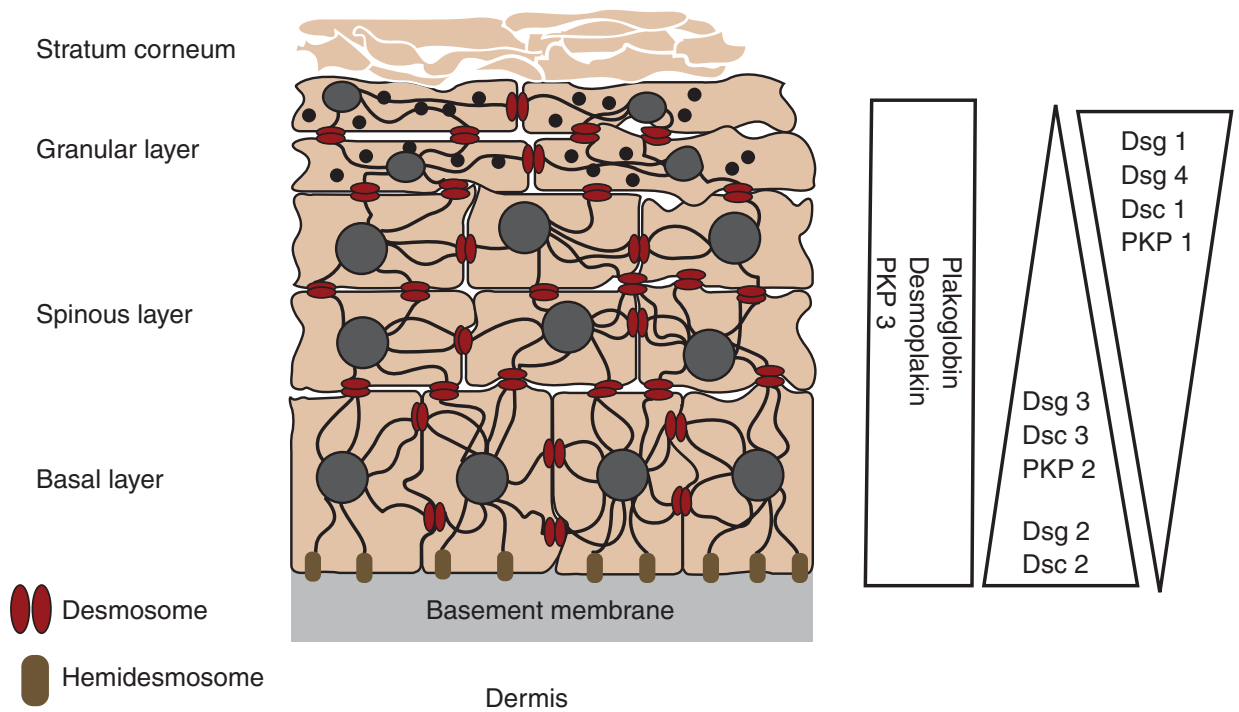

Figure 3. Expression patterns of the desmosomal cadherins in the epidermis. The epidermis is a stratified epithelium comprised of four distinct layers - the basal layer, spinous layer, granular layer, and the stratum corneum. Keratin filaments are shown connecting to desmosomes at sites of cell-cell contact and to hemidesmosomes at the basement membrane. The relative expression profiles of the various desmosomal cadherins and plaque proteins in the epidermal layers are depicted on the right. (Adapted with permission from Kottke et al. 2006.)

cadherins in development and in adult tissue function. For example, loss of mouse Dsg3 resulted in animals with compromised cellcell adhesion in the oral mucosa, with separation of keratinocytes and weakened desmosomal adhesion (Koch et al. 1997). Ablation of Dsg2, on the other hand, results in embryonic lethality shortly after implantation (Eshkind et al. 2002). Interestingly, this lethality on loss of Dsg2 was attributed in part to decreased embryonic stem cell proliferation, suggesting roles of Dsg2 that transcend desmosomal adhesive functions.

Desmocollins also play an important role in the structural integrity of the epidermis and in the control of keratinocyte proliferation and differentiation. Mice lacking Dsc1, which is normally expressed in the upper layers of the epidermis, display loss of cell-cell adhesion in the granular layer as well as hyperproliferation, hair follicle degeneration, and increased expression of the wound keratins, 6 and 16 (Chidgey et al. 2001). Similarly, the conditional ablation of DSC3 in mouse epidermis also resulted in epidermal fragility and hair loss (Chen et al. 2008).
Even more remarkable is that complete loss of Dsc3 expression resulted in preimplantation embryonic lethality (E2.5), strongly suggesting nondesmosomal roles for Dsc3 during development (Den et al. 2006). Lastly, misexpression of Dsc3 in the suprabasal epidermis results in keratinocyte hyperproliferation and abnormal differentiation. These defects were attributed to increased stability of $\beta$-catenin, an adherens junction protein known to regulate gene expression and epithelial proliferation (Hardman et al. 2005).

The studies outlined in this section using mouse genetic models implicate desmosomal cadherins in epithelial proliferation and differentiation, and in the robust cell-cell adhesion that is required for tissue integrity. As discussed next, a number of inherited and acquired human diseases confirm these conclusions.

\section{Desmosomal Cadherins and Disease}

During the past $10-15$ years, a wide range of studies revealed roles for desmosomal cadherins in human diseases, particularly in disorders 
affecting the heart and the skin. Mutations in three of the desmoglein isoforms cause inherited disorders. Loss of DSG4 is associated with defective hair-follicle differentiation (Kljuic et al. 2003), whereas DSG1 haploinsufficiency leads to striate palmoplantar keratoderma, an epidermal-thickening disease (Rickman et al. 1999). The localized impact of these mutations in DSG1 and DSG4 on the skin is consistent with the tissue expression patterns of these genes (Fig. 3). In contrast, mutations in DSG2 result in arrhythmogenic right ventricular cardiomyopathy (ARVC) (Awad et al. 2006; Pilichou et al. 2006).

In this case, heart manifestation of disease most likely reflects a strict requirement for Dsg2 function in resisting mechanical stresses associated with cardiac contraction. To date, no examples of DSG3 mutations have been reported. However, Simpson and colleagues recently reported the first case of a human mutation in a desmocollin (DSC2) and its association with autosomal recessive ARVC (Simpson et al. 2008). Similar to the mouse genetic models described previously, these human disorders further reveal functions for desmosomal cadherins in both tissue integrity and differentiation.

In addition to inherited disorders, desmosomal cadherins are also targets of autoimmune disease. Pemphigus is a class of diseases in which autoantibodies target the desmosomal cadherins, predominantly Dsg1 and Dsg3. The term "pemphigus" is derived from the Greek word "pemphix," which means blister. These pathologies include pemphigus foliaceus $(\mathrm{PF})$ and pemphigus vulgaris (PV) (Prajapati and Mydlarski 2008). PV is a potentially fatal autoimmune skin disease characterized by circulating autoantibodies (IgG) against Dsg3 and sometimes Dsg1 (Amagai et al. 1991; Amagai 1996; Amagai 1999; Amagai 2002; Payne et al. 2004). PV is characterized histologically by suprabasal acantholysis (loss of cell-cell adhesion) and clinically by mucous membrane erosion and epidermal blisters (Stanley and Amagai 2006). In contrast, PF patients show antibodies against Dsg1 and present clinically with superficial blisters of the epidermis and without mucous membrane involvement. The difference in the clinical presentation in PV and PF is thought to be because of the tissue distribution of Dsg1 and Dsg3 (Mahoney et al. 1999). Nonetheless, in both cases, autoantibodies directed against the desmosomal cadherins are known to cause loss of keratinocyte adhesion (Amagai et al. 2006).

Pemphigus is relatively rare, but these diseases have proven important in revealing functions of desmogleins as well as the mechanisms by which desmosome function is regulated. For example, the fact that IgG against Dsg3 and Dsg1 causes loss of epidermal integrity substantiates a key role for these proteins in epithelial cell-cell adhesion strength. Furthermore, advances in understanding the molecular mechanisms of pemphigus led Stanley and Amagai to correctly predict that bullous impetigo, a common infection caused by a staphylococcal bacterium, causes epidermal blistering by targeting Dsg 1 . The bacterium produces exfoliative toxin, a serine protease that cleaves the Dsg1 extracellular domain. The cleavage results in blistering in the granular layer that is histologically identical to the acantholysis caused by Dsg1 autoantibodies in PF patients (Amagai et al. 2000; Stanley and Amagai 2006). Thus, epidermal integrity is compromised by either autoantibodies or bacterial toxins that target desmogleins.

Although great strides have been made in identifying the pemphigus antigens, it remains unclear exactly how pemphigus antibodies cause loss of adhesion. One likely explanation is that antibody binding to the Dsg extracellular domain simply blocks adhesion by steric hindrance. However, this hypothesis is called into question by several observations. For example, PV IgG are unable to induce acantholysis in plakoglobin-null cells (Caldelari et al. 2001). In addition, human keratinocytes treated with PV IgG at $4^{\circ} \mathrm{C}$ do not show loss of cell-cell adhesion until the cells are shifted to $37^{\circ} \mathrm{C}$, suggesting that keratinocyte responses are required in order for the antibodies to cause loss of adhesion (Calkins et al. 2006). Other studies have implicated a role for signal transduction in mediating PV-induced acantholysis. 
Pemphigus IgG binding has been shown to cause activation of numerous cell signaling pathways.

Work by the Rubenstein laboratory has illustrated that PV IgG binding induced phosphorylation of heat shock protein 27 (HSP27) via p38 mitogen-activating protein kinase (p38MAPK) (Berkowitz et al. 2006; Berkowitz et al. 2007; Berkowitz et al. 2008). p38MAPK has also been shown to be involved in phosphorylation of Dsg3 in response to PV IgG (Kawasaki et al. 2006). Furthermore, inhibition of p38MAPK activity prevents keratin retraction, actin reorganization, and formation of epidermal blisters in a mouse model (Berkowitz et al. 2005; Berkowitz et al. 2006). Similarly, signaling through the c-myc pathway has also been implicated in PV pathogenesis (Williamson et al. 2006). These studies suggest that either the activation of signaling pathways on autoantibody binding to the desmosomal cadherins causes loss of adhesion, or alternatively, that manipulation of intracellular signaling pathways can bolster baseline adhesion strength and prevent blistering caused by pemphigus IgG. Either scenario implies that pemphigus patients could be treated by targeting these regulatory networks.

A number of observations have also illustrated that pemphigus IgG binding may interfere with the normal turnover of the desmogleins. Early studies found that PV IgG were internalized after binding to the surface of keratinocytes (Patel et al. 1984; Iwatsuki et al. 1989; Sato et al. 2000). Work from our lab has shown that PV IgG binding results in clathrin independent endocytosis of Dsg3 and subsequent routing of the cadherin to a lysosomal compartment for degradation (Calkins et al. 2006; Delva et al. 2008). Furthermore, blocking Dsg3 endocytosis (Delva et al. 2008) or up-regulating Dsg3 biosynthesis by exogenously expressing Dsg3 prevents keratinocyte loss of adhesion in response to PV IgG (JM Jennings and A. Kowalczyk, unpubl.).

Work performed by Payne and Kitajima also lends support to the impact of PV IgG on desmosomal assembly, as PV IgG causes internalization of newly synthesized pools of Dsg3
(Sato et al. 2000; Mao et al. 2008). Altogether, these findings suggest that pemphigus IgG disrupt the normal turnover and assembly of desmosomes. In fact, a growing body of evidence suggests that regulation of post Golgi trafficking of cadherins is a key mechanism by which cell adhesion is regulated during development and disease (Mosesson et al. 2008; Delva and Kowalczyk 2009).

\section{ARMADILLO FAMILY OF PROTEINS}

Cadherins, like other transmembrane adhesion proteins, require cytoplasmic interactions for strong adhesion and cytoskeletal attachment. In the desmosome, the cytoplasmic associations with the cadherins are partly mediated by the armadillo family proteins, plakoglobin, and the plakophilins. Armadillo was originally discovered as a regulator of segment polarity in Drosophila, and later found to be the homolog of the vertebrate junctional and signaling proteins, $\beta$-catenin and plakoglobin (Peifer et al. 1992). The armadillo proteins are characterized by the presence of a central domain, containing repeating units of a 42 amino acid sequence homology domain (arm repeats) (Peifer et al. 1992). These proteins include $\beta$-catenin, plakoglobin $(\gamma$-catenin $)$, p120catenin, p0071, ARVC, $\delta$-catenin, and the plakophilins 1-3 (PKP 1-3) (Hatzfeld 2005; Hatzfeld 2007). The roles of these proteins in the desmosome appear to be to facilitate the tethering of desmoplakin and keratin intermediate filaments to the desmosome, and to regulate clustering of the desmosomal components. In addition to these structural roles, armadillo proteins also mediate important signal transduction pathways.

\section{Plakoglobin}

Plakoglobin is the best characterized armadillo protein in the desmosome. Structurally, the protein contains 12-arm repeats flanked by distinct amino- and carboxy-terminal domains (Fig. 4) (Peifer et al. 1992; Huber et al. 1997; Garrod and Chidgey 2008). High resolution structural studies of the desmosomal 
E. Delva, D.K. Tucker, and A.P. Kowalczyk
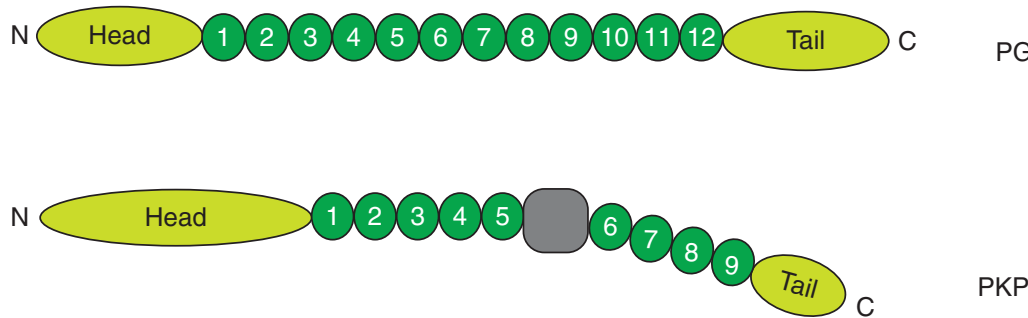

PKP a

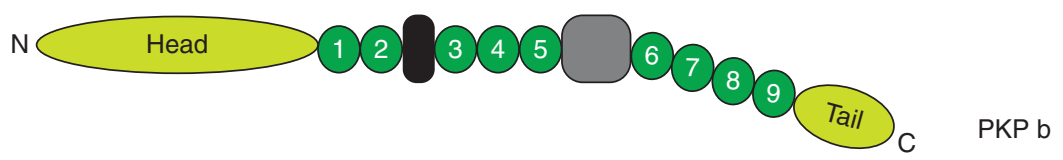

Figure 4. Armadillo protein family members. Plakoglobin (PG) contains 12-arm repeats that are flanked by distinct amino- and carboxy-termini. The plakophilins (PKP) contain 9-arm repeats with an insert between repeats 5 and 6 that introduces a bend into the overall structure. PKP1 and PKP2 exist as two isoforms, each generating a short "a" form and a longer " $\mathrm{b}$ " form, differing by the addition of 21 amino acids in arm repeat three (PKP1) and the addition of 44 amino acids in arm repeat four (PKP2).

cadherin-plakoglobin complex have not yet been reported, but deletion mutagenesis studies suggest that the plakoglobin amino-terminus and several arm repeats near the carboxyterminus are key for desmosomal cadherin binding (Chitaev et al. 1996; Wahl et al. 1996; Witcher et al. 1996). Although plakoglobin localizes to desmosomes and adherens junctions, its affinity for desmosomal cadherins is several times greater than for E-cadherin (Chitaev et al. 1996).

The central armadillo domain of plakoglobin also interacts with desmoplakin, which tethers intermediate filaments to the desmosomal plaque (Kowalczyk et al. 1997; Smith and Fuchs 1998; Bornslaeger et al. 2001). These data have been used to generate models in which the desmosomal cadherins are linked to desmoplakin and the intermediate filament cytoskeleton in a simple linear chain. This type of linkage was also thought to be responsible for classical cadherin associations with actin, whereby $\beta$-catenin functioned in an analogous manner to link E-cadherin to actin binding proteins such as $\alpha$-catenin. However, this model was called into question by studies from the Nelson and Weis laboratories (Drees et al. 2005; Yamada et al. 2005).

Thus, it remains speculative as to whether plakoglobin associates with the desmosomal cadherins and the desmoplakin-intermediate filament complex simultaneously. Nonetheless, plakoglobin clearly plays a key role in desmosome assembly as revealed by both human diseases and mouse genetic model systems (see the following).

A critical role for plakoglobin in desmosome assembly in vivo first emerged from plakoglobin knockout studies in mice. Plakoglobin null animals die because of fragility of the myocardium (Bierkamp et al. 1996; Ruiz et al. 1996). These mice also show acantholysis, indicative of compromised desmosome function (Acehan et al. 2008). In some genetic backgrounds, mouse pups are born but show serious epidermal fragility, heart defects, and early postnatal lethality. Consistent with these findings, Naxos disease, an autosomal recessive disease characterized by ARVC, woolly hair, and palmoplantar keratoderma, develops as a result of a plakoglobin gene mutation leading to the truncation of the carboxy-terminus of the protein (McKoy et al. 2000). The heart defect occurs as a result of fragility of the myocyte syncytium, which leads to its degradation and fibrofatty replacement (Kottke et al. 2006). Although the palmoplantar keratoderma phenotype may result from weakened cell adhesion, the epidermal manifestations seen in Naxos patients are not as severe as the 
plakoglobin-null mice (Kottke et al. 2006). Interestingly, Naxos disease patients also show woolly hair, in which the hair shaft is lighter and finer than unaffected individuals. The precise mechanism by which this hair defect occurs is unknown, but plakoglobin and $\beta$-catenin have both been implicated in hair follicle formation.

Both $\beta$-catenin and plakoglobin function as regulators of the T-cell factor (TCF) family of transcription factors and modulators of Wnt growth factor signaling, a pathway known to be important in hair follicle development (Huelsken and Behrens 2002; Chien et al. 2009). Interestingly, plakoglobin overexpression in mouse epidermis decreases keratinocyte proliferation and shortens the anagen phase of the hair cycle (Charpentier et al. 2000), whereas $\beta$-catenin overexpression causes hyperproliferation and hair follicle differentiation (Gat et al. 1998). These observations suggest that either the balance between plakoglobin and $\beta$-catenin signaling is misregulated in Naxos patients, or that the hair defect is caused by loss of proliferation and/or adhesion in the hair follicle and shaft.

\section{Plakophilins}

The other armadillo members represented in the desmosome are the plakophilins (PKPs). Based on the number and organization of the central armadillo repeat domain, the plakophilins are considered to be members of the p120-catenin subfamily of armadillo proteins. In contrast to p120-catenin, the plakophilins are predominantly found at desmosomes instead of adherens junctions, with PKP1 and 2 also localizing to the nucleus. Plakophilins $1-3$ share approximately $55 \%$ sequence similarity within the armadillo repeats and approximately $50 \%$ sequence similarity with the p120-catenin arm domain (Hatzfeld 2007). Both PKP1 and 2 exist as two isoforms, each generating a short "a" form and a longer "b" form, differing in the addition of 21 amino acids in arm repeat three (PKP1) and the addition of 44 amino acids in arm repeat four (PKP2) (Mertens et al. 1996; Schmidt et al.
1997). Based on structural analysis, the plakophilins contain 9 arm repeat domains (Fig. 4) (Choi and Weis 2005).

Although the armadillo domain of plakoglobin, $\beta$-catenin, and other p120-catenin family members all function as a scaffold for numerous binding partners, plakophilin binding partners that have been identified to date associate with the plakophilin aminoterminal head domain. Thus, the precise role of the central armadillo domain of the plakophilins remains mysterious.

Similar to the desmosomal cadherins, the plakophilins show tissue and differentiationspecific patterns of expression. PKP1 is more highly expressed in the suprabasal layers of stratified epithelia, whereas PKP2 is expressed in simple epithelia, the lower layers of stratified epithelia, and in nonepithelial tissues such as cardiac muscle and lymph nodes (Heid et al. 1994; Mertens et al. 1996; Schmidt et al. 1997; Mertens et al. 1999; Franke et al. 2007). PKP3 resides in simple and stratified epithelia, showing uniform expression throughout the epidermis (Fig. 3) (Bonne et al. 1999; Schmidt et al. 1999). It is unclear how these expression patterns are integrated with potential differences in functions of the various plakophilin isoforms.

An obvious morphological difference between desmosomes and adherens junctions is the remarkably electron-dense and highly organized disk-shaped plaque that characterizes the desmosome. Plakophilins are likely to play a key role in the clustering that drives the formation of this highly ordered structure. This function is particularly evident in PKP1. The aminoterminal head domain of PKP1 associates with Dsg1, desmoplakin, and keratin intermediate filaments (Hatzfeld et al. 2000). The binding of the PKP1 head domain to desmoplakin appears particularly robust, and this binding event drives desmoplakin recruitment to cellcell junctions (Kowalczyk et al. 1999b; Hatzfeld et al. 2000; Wahl 2005).

Based on these interactions, a model has been proposed in which plakophilins play a role in the lateral interactions between desmosomal plaque complexes (Kowalczyk et al. 1999b). 
In support of this model, PKP1 is highly expressed in the suprabasal layers of the epidermis where desmosomes are larger and more numerous than in the lower layers of the tissue. In contrast, PKP3 overexpression does not result in larger desmosomes or an increase in desmosome number (Bonne et al. 1999; Schmidt et al. 1999; Bonne et al. 2003). However, PKP3 interacts with the largest number of desmosomal proteins, including desmoplakin, plakoglobin, all three desmoglein proteins, Dsc 3a and 3b, and Dsc 1a and 2a (Hatzfeld 2007). PKP2 is also less efficient than PKP1 at recruiting desmoplakin and other desmosomal proteins to the plasma membrane (Chen et al. 2002), suggesting differences in plakophilin isoform function. Recent studies from the Green lab indicate that PKP2 plays an important role in transport of desmoplakin to the plasma membrane during desmosome assembly. In this model system, PKP2 functions as a scaffold for PKC- $\alpha$ and thereby regulates desmoplakin association with intermediate filaments (Godsel et al. 2005; Bass-Zubek et al. 2008; see also Green et al. 2009). Additional studies will be needed to determine whether PKP1 and PKP3 also regulate assembly through PKC- $\alpha$.

The importance of plakophilins in maintaining desmosomal integrity is underscored by various diseases and/or defective cellular processes that are associated with mutations in each of the plakophilins. For example, patients who suffer from a severe autosomal recessive ectodermal dysplasia and skin fragility syndrome were found to have mutations in PKP1 (McGrath et al. 1997; McGrath et al. 1999).

The dysplasia suggests that in addition to its role in regulating desmosome stability, PKP1 may also regulate epidermal morphogenesis. Because PKP2 is the only isoform expressed in the heart, mutations associated with this particular plakophilin cause ARVC (Gerull et al. 2004). In most cases, the mutations are found within the carboxy-terminus of the PKP2 protein, although other mutations have been observed. Based on experiments in which the gene encoding PKP2 is ablated in mice, the effects seen in ARVC patients are likely the result of mechanical fragility. These mice display mid-gestational embryonic lethality caused by cardiac patterning defects and fragility of the myocardium (Grossmann et al. 2004). PKP2-null mice also display retraction of intermediate filaments from the plasma membrane, further illustrating the importance of plakophilins in desmoplakin recruitment and intermediate filament tethering to the desmosome plaque. Although no human pathologies are associated with mutations in PKP3, conditional ablation of PKP3 in mouse epidermis resulted in defective hair follicle morphogenesis, increased keratinocyte proliferation, and desmoplakin mislocalization. These mice are also more susceptible to dermatitis (skin inflammation) and secondary alopecia (hair loss) (Sklyarova et al. 2008).

Emerging evidence indicates that plakophilins also function outside of the desmosome. Plakophilins, especially PKP1, show striking nuclear localization, although it is currently unclear what functions these proteins may play in gene regulation and/or nuclear structure (Mertens et al. 1996; Hatzfeld et al. 2000).

In addition, PKP2 was found in RNA polymerase III complexes and PKP3 in cytoplasmic particles containing RNA-binding proteins (Mertens et al. 2001; Hofmann et al. 2006). Additional studies are clearly warranted to understand how these associations and nuclear localization are integrated with function in the desmosome, and more broadly, with epithelial cell contributions to tissue architecture.

\section{DESMOPLAKIN}

Desmoplakin is the most abundant component of the desmosome (Mueller and Franke 1983) and serves as the key linker between intermediate filaments and the plasma membrane (Bornslaeger et al. 1996; Gallicano et al. 1998; Vasioukhin et al. 2001). Desmoplakin is among the founding members of a large family of proteins termed the plakin family of cytolinkers (Green et al. 1992b; Sonnenberg and Liem 2007). These large molecules link cytoskeletal networks to the plasma membrane 
and integrate actin, microtubules, and intermediate filaments. Desmoplakin contains globular amino- and carboxy-termini, connected by a central, $\alpha$-helical coiled-coil rod domain. The amino-terminal head domain provides binding sites for plakoglobin and plakophilins, and thereby targets the protein to the cadherinarmadillo complex at the desmosome (Bornslaeger et al. 1996; Kowalczyk et al. 1999a; Bornslaeger et al. 2001; Holthofer et al. 2007). The carboxy-terminal tail contains three plakin repeat domains (PRDs; $\mathrm{A}, \mathrm{B}, \mathrm{C}$ ), as well as a glycine-serine-arginine rich domain thought to regulate desmoplakin binding to intermediate filaments (Fig. 5) (Choi et al. 2002; Getsios et al. 2004b; Yin and Green 2004). There are two desmoplakin isoforms (I and II), with desmoplakin II missing approximately two-thirds of the rod domain (Green et al. 1992a).

Similar to the "a" and " $b$ " forms of desmocollins, desmoplakin I and II are produced as a result of alternative RNA splicing. Although both isoforms of desmoplakin are widely expressed in numerous tissues, desmoplakin II is absent from the heart and its expression is lower in simple epithelia (Angst et al. 1990).

Several studies highlight the importance of desmoplakin in desmosome structure and function. Mice lacking desmoplakin die shortly after implantation at day E6.5 and show fewer desmosomes, compared with wild-type mice (Gallicano et al. 1998). Furthermore, desmosomes that are observed in desmoplakinnull embryos do not attach to intermediate filaments. These observations support in vitro studies and illustrate the importance of desmoplakin in linking intermediate filaments to the plasma membrane (Bornslaeger et al. 1996). There is also striking evidence that desmoplakin plays roles in tissue morphogenesis. Desmoplakin-null embryos fail to undergo the massive increase in cell proliferation normally observed at E5-6, and other studies have illustrated that desmoplakin is pivotal in the development of the epidermis, neuroepithelium, heart and blood vessels (Gallicano et al. 2001; Vasioukhin et al. 2001). Interestingly, loss of desmoplakin dramatically alters actin organization at the cell periphery, demonstrating that key aspects of cross-talk between desmosomes and adherens junctions are somehow mediated by desmoplakin during epithelial sheet formation (Vasioukhin et al. 2001).

Perhaps not surprisingly, there are a number of human genetic disorders associated with desmoplakin mutations, with varying degrees of severity, depending on the particular mutation generated (Lai Cheong et al. 2005). For example, desmoplakin haploinsufficiency causes striate palmoplantar keratoderma (Armstrong et al. 1999; Whittock et al. 1999).

Compound heterozygosity with aminoterminal missense mutations and carboxyterminal nonsense mutations leads to a more severe keratoderma, skin fragility, and woolly hair/alopecia (Whittock et al. 2002). One patient harboring compound heterozygous mutations that truncated the desmoplakin

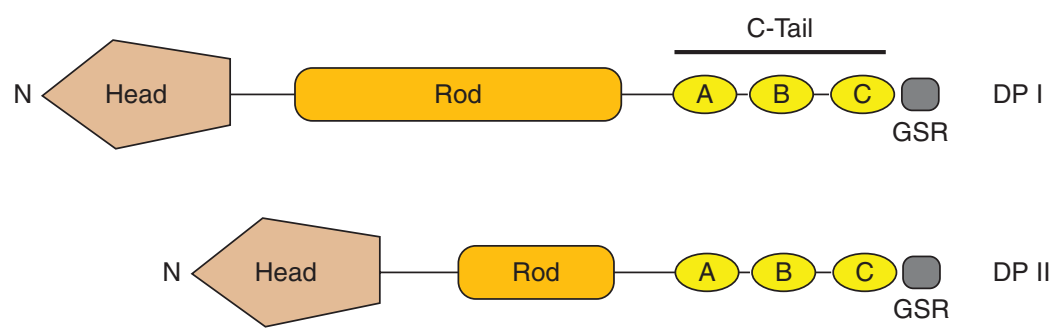

Figure 5. Desmoplakin. Shown above are the different domains that form the two desmoplakin isoforms, DP I and II. The two isoforms differ in the length of the central rod domain (Rod), with DP II missing approximately two-thirds of the Rod domain. The carboxy-terminal tail (C-Tail) contains three plakin repeat domains (A, B, C), as well as a glycine-serine-arginine rich domain (GSR) thought to regulate desmoplakin binding to intermediate filaments. The amino-terminal globular head domain (Head) mediates proteinprotein interactions. See text for additional details. 
carboxy-terminus presented with severe acantholytic epidermolysis bullosa. This lethal disorder included complete alopecia (lack of hair), neonatal teeth, nail loss, and death 10 days postpartum because of transcutaneous fluid loss as a result of extensive skin erosion (Jonkman et al. 2005). This finding illustrates that attachment of intermediate filaments to the desmosome (via the desmoplakin carboxy-terminus) is necessary for supporting strong cell-cell attachment, particularly in the epidermis.

\section{CONCLUDING REMARKS}

The desmosome is a remarkable protein complex that was appreciated by early microscopists as a key structural element in a wide range of epithelial tissues. Work in the 1970s and 1980s led the identification and localization of the major desmosomal components. This foundation led to the employment of molecular and genetic approaches in the 1990s to identify desmosomal protein binding partners and roles during development.

A number of exciting and important challenges have emerged with our growing understanding of desmosome biology and with the development of new tools and model systems. For example, desmosomes are clearly not static structures, even though they mediate robust adhesion.

Significant effort is being focused on the mechanisms by which individual desmosomal components traffic to and from the desmosome, and how these dynamics are coordinated with the assembly of other intercellular junctions, including adherens junctions, tight junctions, and gap junctions. One of the most exciting and perhaps important issues to address is how desmosomal proteins contribute to tissue patterning and epithelial homeostasis. As outlined above, mutations in many of the desmosomal genes result in keratodermas or ectodermal dysplasia. Whether these changes in epithelial structure are compensatory, or if they reflect direct loss- or gain-of-function phenotypes because of misregulation of signaling pathways in the absence of the wild-type gene is unclear. A related issue arises when one considers the number of desmosomal cadherins and plakophilin isoforms that show tissuespecific expression patterns. It is clear that the correct spatial and temporal patterns of expression of these isoforms is driven by tissue- and differentiation-specific functions of each molecule. The continued use of human and mouse genetics, in combination with emerging studies of desmosome dynamics, promises to advance our understanding of how specific desmosomal proteins function at the molecular, cellular, and tissue levels.

\section{ACKNOWLEDGMENTS}

The authors are grateful for advice and support provided by Drs. Kathleen Green, Spiro Getsios, and members of the Kowalczyk laboratory. Work in the Kowalczyk lab is supported by National Institute of Health (NIH) R01 AR048266 and R01 AR050501. ED was supported by NIH F31 CA110278 and DKT was supported by NIH T32 GM008367.

\section{REFERENCES}

Acehan D, Petzold C, Gumper I, Sabatini DD, Muller EJ, Cowin P, Stokes DL. 2008. Plakoglobin is required for effective intermediate filament anchorage to desmosomes. J Invest Dermatol 128: 2665-2675.

Al-Amoudi A, Frangakis AS. 2008. Structural studies on desmosomes. Biochem Soc Trans 36: 181-187.

Amagai M. 1996. Pemphigus: Autoimmunity to epidermal cell adhesion molecules. Adv Dermatol 11: 319-352; discussion 353.

Amagai M. 1999. Autoimmunity against desmosomal cadherins in pemphigus. J Dermatol Sci 20: 92-102.

Amagai M. 2002. Pemphigus as a paradigm of autoimmunity and cell adhesion. Keio J Med 51: 133-139.

Amagai M, Ahmed AR, Kitajima Y, Bystryn JC, Milner Y, Gniadecki R, Hertl M, Pincelli C, Fridkis-Hareli M, Aoyama Y, et al. 2006. Are desmoglein autoantibodies essential for the immunopathogenesis of pemphigus vulgaris, or just 'witnesses of disease'? Exp Dermatol 15: 815 .

Amagai M, Klaus-Kovtun V, Stanley JR. 1991. Autoantibodies against a novel epithelial cadherin in pemphigus vulgaris, a disease of cell adhesion. Cell 67: 869-877.

Amagai M, Matsuyoshi N, Wang ZH, Andl C, Stanley JR. 2000. Toxin in bullous impetigo and staphylococcal scalded-skin syndrome targets desmoglein 1. Nat Med 6: $1275-1277$. 
Angst BD, Nilles LA, Green KJ. 1990. Desmoplakin II expression is not restricted to stratified epithelia. $J$ Cell Sci 97: 247-257.

Armstrong DK, McKenna KE, Purkis PE, Green KJ, Eady RA, Leigh IM, Hughes AE. 1999. Haploinsufficiency of desmoplakin causes a striate subtype of palmoplantar keratoderma. [erratum appears in Hum Mol Genet 1999 May;8(5):943]. Human Mol Gen 8: 143-148.

Awad MM, Dalal D, Cho E, Amat-Alarcon N, James C, Tichnell C, Tucker A, Russell SD, Bluemke DA, Dietz HC, et al. 2006. DSG2 mutations contribute to arrhythmogenic right ventricular dysplasia/cardiomyopathy. Am J Human Gen 79: 136-142.

Bass-Zubek AE, Green KJ. 2007. Biochemical characterization of the desmosome. J Invest Dermatol 127: E4-E5.

Bass-Zubek AE, Hobbs RP, Amargo EV, Garcia NJ, Hsieh SN, Chen X, Wahl JK, Denning MF 3rd, Green KJ. 2008. Plakophilin 2: A critical scaffold for PKC alpha that regulates intercellular junction assembly. $\mathrm{JJ}$ Cell Biol 181: 605-613.

Berkowitz P, Chua M, Liu Z, Diaz LA, Rubenstein DS. 2008. Autoantibodies in the autoimmune disease pemphigus foliaceus induce blistering via p38 mitogen-activated protein kinase-dependent signaling in the skin. $A m J$ Pathol 173: 1628-1636.

Berkowitz P, Diaz LA, Hall RP, Rubenstein DS. 2007. Induction of p38MAPK and HSP27 phosphorylation in pemphigus patient skin. J Investig Dermatol 128: $738-740$.

Berkowitz P, Hu P, Liu Z, Diaz LA, Enghild JJ, Chua MP, Rubenstein DS. 2005. Desmosome signaling. Inhibition of p38MAPK prevents pemphigus vulgaris IgG-induced cytoskeleton reorganization. J Biol Chem 280: $23778-$ 23784.

Berkowitz P, Hu P, Warren S, Liu Z, Diaz LA, Rubenstein DS. 2006. p38MAPK inhibition prevents disease in pemphigus vulgaris mice. Proc Natl Acad Sci 103: 1285512860.

Bierkamp C, McLaughlin KJ, Schwarz H, Huber O, Kemler R. 1996. Embryonic heart and skin defects in mice lacking plakoglobin. Developmental biology 180: $780-785$.

Bonne S, Gilbert B, Hatzfeld M, Chen X, Green KJ, van Roy F. 2003. Defining desmosomal plakophilin-3 interactions. J Cell Biol 161: 403-416.

Bonne S, van Hengel J, Nollet F, Kools P, van Roy F. 1999. Plakophilin-3, a novel armadillo-like protein present in nuclei and desmosomes of epithelial cells. J Cell Sci 112: $2265-2276$

Bornslaeger EA, Corcoran CM, Stappenbeck TS, Green KJ. 1996. Breaking the connection: Displacement of the desmosomal plaque protein desmoplakin from cell-cell interfaces disrupts anchorage of intermediate filament bundles and alters intercellular junction assembly. J Cell Biol 134: 985-1001.

Bornslaeger EA, Godsel LM, Corcoran CM, Park JK, Hatzfeld M, Kowalczyk AP, Green KJ. 2001. Plakophilin 1 interferes with plakoglobin binding to desmoplakin, yet together with plakoglobin promotes clustering of desmosomal plaque complexes at cell-cell borders. J Cell Sci 114: 727-738.
Brennan D, Hu Y, Joubeh S, Choi YW, Whitaker-Menezes D, O'Brien T, Uitto J, Rodeck U, Mahoney MG. 2007. Suprabasal Dsg2 expression in transgenic mouse skin confers a hyperproliferative and apoptosis-resistant phenotype to keratinocytes. J Cell Sci 120: 758-771.

Caldelari R, de Bruin A, Baumann D, Suter MM, Bierkamp C, Balmer V, Muller E. 2001. A central role for the armadillo protein plakoglobin in the autoimmune disease pemphigus vulgaris. J Cell Biol 153: 823-834.

Calkins CC, Setzer SV. 2007. Spotting desmosomes: The first 100 years. J Invest Dermatol 127: E2-E3.

Calkins CC, Setzer SV, Jennings JM, Summers S, Tsunoda K, Amagai M, Kowalczyk AP. 2006. Desmoglein endocytosis and desmosome disassembly are coordinated responses to pemphigus autoantibodies. J Biol Chem 281: $7623-7634$.

Charpentier E, Lavker RM, Acquista E, Cowin P. 2000. Plakoglobin suppresses epithelial proliferation and hair growth in vivo. J Cell Biol 149: 503-520.

Chen J, Den Z, Koch PJ. 2008. Loss of desmocollin 3 in mice leads to epidermal blistering. J Cell Sci 121: 2844-2849.

Chen X, Bonne S, Hatzfeld M, van Roy F, Green KJ. 2002. Protein binding and functional characterization of plakophilin 2. Evidence for its diverse roles in desmosomes and beta-catenin signaling. J Biol Chem 277: 10512-10522.

Chidgey M, Brakebusch C, Gustafsson E, Cruchley A, Hail C, Kirk S, Merritt A, North A, Tselepis C, Hewitt J, et al. 2001. Mice lacking desmocollin 1 show epidermal fragility accompanied by barrier defects and abnormal differentiation. J Cell Biol 155: 821-832.

Chien AJ, Conrad WH, Moon RT. 2009. A Wnt survival guide: From flies to human disease. $J$ Invest Dermato doi: $10.1038 /$ jid.2008.445.

Chitaev NA, Leube RE, Troyanovsky RB, Eshkind LG, Franke WW, Troyanovsky SM. 1996. The binding of plakoglobin to desmosomal cadherins: Patterns of binding sites and topogenic potential. J Cell Biol 133: 359-369.

Chitaev NA, Troyanovsky SM. 1997. Direct Ca2+dependent heterophilic interaction between desmosomal cadherins, desmoglein and desmocollin, contributes to cell-cell adhesion. J Cell Biol 138: 193-201.

Choi HJ, Park-Snyder S, Pascoe LT, Green KJ, Weis WI. 2002. Structures of two intermediate filament-binding fragments of desmoplakin reveal a unique repeat motif structure. Nat Structural Biol 9: 612-620.

Choi HJ, Weis WI. 2005. Structure of the armadillo repeat domain of plakophilin 1. J Mol Biol 346: 367-376.

Collins JE, Legan PK, Kenny TP, MacGarvie J, Holton JL, Garrod DR. 1991. Cloning and sequence analysis of desmosomal glycoproteins 2 and 3 (desmocollins): Cadherin-like desmosomal adhesion molecules with heterogeneous cytoplasmic domains. J Cell Biol 113: 381-391.

Cowin P, Burke B. 1996. Cytoskeleton-membrane interactions. Current Opinion Cell Biol 8: 56-65.

Delva E, Jennings JM, Calkins CC, Kottke MD, Faundez V, Kowalczyk AP. 2008. Pemphigus vulgaris IgG-induced desmoglein-3 endocytosis and desmosomal disassembly are mediated by a clathrin- and dynamin-independent mechanism. Biol Chem 283: 18303-18313. 
E. Delva, D.K. Tucker, and A.P. Kowalczyk

Delva E, Kowalczyk AP. 2009. Regulation of cadherin trafficking. Traffic 10: 259-267.

Den Z, Cheng X, Merched-Sauvage M, Koch PJ. 2006. Desmocollin 3 is required for pre-implantation development of the mouse embryo. J Cell Sci 119: 482-489.

Drees F, Pokutta S, Yamada S, Nelson WJ, Weis WI. 2005. Alpha-catenin is a molecular switch that binds E-cadherin-beta-catenin and regulates actin-filament assembly. Cell 123: 903-915.

Elias PM, Matsuyoshi N, Wu H, Lin C, Wang ZH, Brown BE, Stanley JR. 2001. Desmoglein isoform distribution affects stratum corneum structure and function. J Cell Biol 153: 243-249.

Eshkind L, Tian Q, Schmidt A, Franke WW, Windoffer R, Leube RE. 2002. Loss of desmoglein 2 suggests essential functions for early embryonic development and proliferation of embryonal stem cells. Eur J Cell Biol 81: 592-598.

Franke WW, Schmid E, Grund C, Muller H, Engelbrecht I, Moll R, Stadler J, Jarasch ED. 1981. Antibodies to high molecular weight polypeptides of desmosomes: Specific localization of a class of junctional proteins in cells and tissue. Differentiation 20: 217-241.

Franke WW, Schumacher H, Borrmann CM, Grund C, Winter-Simanowski S, Schlechter T, Pieperhoff S, Hofmann I. 2007. The area composita of adhering junctions connecting heart muscle cells of vertebrates - III: Assembly and disintegration of intercalated disks in rat cardiomyocytes growing in culture. Eur J Cell Biol 86: 127-142.

Gallicano GI, Bauer C, Fuchs E. 2001. Rescuing desmoplakin function in extra-embryonic ectoderm reveals the importance of this protein in embryonic heart, neuroepithelium, skin and vasculature. Development 128: 929-941.

Gallicano GI, Kouklis P, Bauer C, Yin M, Vasioukhin V, Degenstein L, Fuchs E. 1998. Desmoplakin is required early in development for assembly of desmosomes and cytoskeletal linkage. J Cell Biol 143: 2009-2022.

Garrod D, Chidgey M. 2008. Desmosome structure, composition and function. Bioch biophys Acta 1778: 572-587.

Gat U, DasGupta R, Degenstein L, Fuchs E. 1998. De Novo hair follicle morphogenesis and hair tumors in mice expressing a truncated beta-catenin in skin. Cell 95: 605-614.

Gerull B, Heuser A, Wichter T, Paul M, Basson CT, McDermott DA, Lerman BB, Markowitz SM, Ellinor PT, MacRae CA, et al. 2004. Mutations in the desmosomal protein plakophilin-2 are common in arrhythmogenic right ventricular cardiomyopathy. Nat Gen 36: $1162-1164$.

Getsios S, Amargo EV, Dusek RL, Ishii K, Sheu L, Godsel LM, Green KJ. 2004a. Coordinated expression of desmoglein 1 and desmocollin 1 regulates intercellular adhesion. Differentiation 72: 419-433.

Getsios S, Huen AC, Green KJ. 2004b. Working out the strength and flexibility of desmosomes. Nat Rev Mol Cell Biol 5: 271-281.

Godsel LM, Hsieh SN, Amargo EV, Bass AE, PascoeMcGillicuddy LT, Huen AC, Thorne ME, Gaudry CA, Park JK, Myung K, et al. 2005. Desmoplakin assembly dynamics in four dimensions: Multiple phases differentially regulated by intermediate filaments and actin. J Cell Biol 171: 1045-1059.

Green KJ, Jones JC. 1996. Desmosomes and hemidesmosomes: Structure and function of molecular components. FASEB J 10: 871-881.

Green KJ, Simpson CL. 2007. Desmosomes: New perspectives on a classic. J Investig Dermatol 127: 2499-2515.

Green KJ, Stappenbeck TS, Parry DA, Virata ML. 1992a. Structure of desmoplakin and its association with intermediate filaments. J Dermatol 19: 765-769.

Green KJ, Virata ML, Elgart GW, Stanley JR, Parry DA. 1992b. Comparative structural analysis of desmoplakin, bullous pemphigoid antigen and plectin: Members of a new gene family involved in organization of intermediate filaments. Int J Biol Macromolecules 14: 145-153.

Green KJ, Getsios S, Troyanovsky S, Godsel LM. 2009. Intercellular junction assembly, dynamics and homeostasis. Cold Spring Harb Perspect Biol 1: a000125.

Grossmann KS, Grund C, Huelsken J, Behrend M, Erdmann B, Franke WW, Birchmeier W. 2004. Requirement of plakophilin 2 for heart morphogenesis and cardiac junction formation. J Cell Biol 167: 149-160.

Hardman MJ, Liu K, Avilion AA, Merritt A, Brennan K, Garrod DR, Byrne C. 2005. Desmosomal cadherin misexpression alters beta-catenin stability and epidermal differentiation. Mol Cell Biol 25: 969-978.

Hatzfeld M. 2005. The p120 family of cell adhesion molecules. Eur J Cell Biol 84: 205-214.

Hatzfeld M. 2007. Plakophilins: Multifunctional proteins or just regulators of desmosomal adhesion? Bioch Biophys Acta 1773: 69-77.

Hatzfeld M, Haffner C, Schulze K, Vinzens U. 2000. The function of plakophilin 1 in desmosome assembly and actin filament organization. J Cell Biol 149: 209-222.

Heid HW, Schmidt A, Zimbelmann R, Schafer S, Winter-Simanowski S, Stumpp S, Keith M, Figge U, Schnolzer M, Franke WW. 1994. Cell type-specific desmosomal plaque proteins of the plakoglobin family: Plakophilin 1 (band 6 protein). Differentiation 58: $113-131$.

Heupel WM, Zillikens D, Drenckhahn D, Waschke J. 2008. Pemphigus vulgaris IgG directly inhibit desmoglein 3 mediated transinteraction. J Immunol 181: 1825-1834.

Hofmann I, Casella M, Schnolzer M, Schlechter T, Spring H, Franke WW. 2006. Identification of the junctional plaque protein plakophilin 3 in cytoplasmic particles containing RNA-binding proteins and the recruitment of plakophilins 1 and 3 to stress granules. Mol Biol Cell 17: 1388 1398.

Holthofer B, Windoffer R, Troyanovsky S, Leube RE. 2007. Structure and function of desmosomes. Int Rev Cytol 264: $65-163$.

Huber AH, Nelson WJ, Weis WI. 1997. Three-dimensional structure of the armadillo repeat region of beta-catenin. Cell 90: 871-882.

Huelsken J, Behrens J. 2002. The Wnt signalling pathway. J Cell Sci 115: 3977-3978.

Iwatsuki K, Takigawa M, Imaizumi S, Yamada M. 1989. In vivo binding site of pemphigus vulgaris antibodies and their fate during acantholysis. J Am Acad Dermatol 20: $578-582$. 
Jonkman MF, Pasmooij AM, Pasmans SG, van den Berg MP, Ter Horst HJ, Timmer A, Pas HH. 2005. Loss of desmoplakin tail causes lethal acantholytic epidermolysis bullosa. Am J Human Gen 77: 653-660.

Kapprell HP, Cowin P, Franke WW, Ponstingl H, Opferkuch HJ. 1985. Biochemical characterization of desmosomal proteins isolated from bovine muzzle epidermis: Amino acid and carbohydrate composition. Eur J Cell Biol 36: 217-229.

Kawasaki Y, Aoyama Y, Tsunoda K, Amagai M, Kitajima Y. 2006. Pathogenic monoclonal antibody against desmoglein 3 augments desmoglein 3 and p38 MAPK phosphorylation in human squamous carcinoma cell line. Autoimmunity 39: 587-590.

Kljuic A, Bauer RC, Christiano AM. 2004. Genomic organization of mouse desmocollin genes reveals evolutionary conservation. DNA Seq 15: 148-152.

Kljuic A, Bazzi H, Sundberg JP, Martinez-Mir A, O’shaughnessy R, Mahoney MG, Levy M, Montagutelli X, Ahmad W, Aita VM, et al. 2003. Desmoglein 4 in hair follicle differentiation and epidermal adhesion: Evidence from inherited hypotrichosis and acquired pemphigus vulgaris. Cell 113: 249-260.

Koch PJ, Mahoney MG, Ishikawa H, Pulkkinen L, Uitto J, Shultz L, Murphy GF, Whitaker-Menezes D, Stanley JR. 1997. Targeted disruption of the pemphigus vulgaris antigen (desmoglein 3) gene in mice causes loss of keratinocyte cell adhesion with a phenotype similar to pemphigus vulgaris. J Cell Biol 137: 1091-1102.

Kottke MD, Delva E, Kowalczyk AP. 2006. The desmosome: Cell science lessons from human diseases. J Cell Sci 119: 797-806.

Kowalczyk AP, Bornslaeger EA, Borgwardt JE, Palka HL, Dhaliwal AS, Corcoran CM, Denning MF, Green KJ. 1997. The amino-terminal domain of desmoplakin binds to plakoglobin and clusters desmosomal cadherinplakoglobin complexes. J Cell Biol 139: 773-784.

Kowalczyk AP, Bornslaeger EA, Norvell SM, Palka HL, Green KJ. 1999a. Desmosomes: Intercellular adhesive junctions specialized for attachment of intermediate filaments. Int Rev Cytol 185: 237-302.

Kowalczyk AP, Hatzfeld M, Bornslaeger EA, Kopp DS, Borgwardt JE, Corcoran CM, Settler A, Green KJ 1999b. The head domain of plakophilin-1 binds to desmoplakin and enhances its recruitment to desmosomes. Implications for cutaneous disease. J Biol Chem 274: 18145-18148.

Kowalczyk AP, Stappenbeck TS, Parry DA, Palka HL, Virata ML, Bornslaeger EA, Nilles LA, Green KJ. 1994. Structure and function of desmosomal transmembrane core and plaque molecules. Biophys Chem 50: 97-112.

Lai Cheong JE, Wessagowit V, McGrath JA. 2005. Molecular abnormalities of the desmosomal protein desmoplakin in human disease. Clin Exp Dermatol 30: 261-266.

Mahoney MG, Wang Z, Rothenberger K, Koch PJ, Amagai M, Stanley JR. 1999. Explanations for the clinical and microscopic localization of lesions in pemphigus foliaceus and vulgaris. J Clin Invest 103: 461-468.

Mao X, Choi EJ, Payne AS. 2008. Disruption of desmosome assembly by monovalent human pemphigus vulgaris monoclonal antibodies. J Invest Dermatol 129: 908-918.
Marcozzi C, Burdett ID, Buxton RS, Magee AI. 1998. Coexpression of both types of desmosomal cadherin and plakoglobin confers strong intercellular adhesion. J Cell Sci 111: 495-509.

Mathur M, Goodwin L, Cowin P. 1994. Interactions of the cytoplasmic domain of the desmosomal cadherin Dsg1 with plakoglobin. J Biol Chem 269: 14075-14080.

McGrath JA, Hoeger PH, Christiano AM, McMillan JR, Mellerio JE, Ashton GH, Dopping-Hepenstal PJ, Lake BD, Leigh IM, Harper JI, et al. 1999. Skin fragility and hypohidrotic ectodermal dysplasia resulting from ablation of plakophilin 1. Br J Dermatol 140: 297-307.

McGrath JA, McMillan JR, Shemanko CS, Runswick SK, Leigh IM, Lane EB, Garrod DR, Eady RA. 1997. Mutations in the plakophilin 1 gene result in ectodermal dysplasia/skin fragility syndrome. Nat Gen 17: 240-244.

McKoy G, Protonotarios N, Crosby A, Tsatsopoulou A, Anastasakis A, Coonar A, Norman M, Baboonian C, Jeffery S, McKenna WJ. 2000. Identification of a deletion in plakoglobin in arrhythmogenic right ventricular cardiomyopathy with palmoplantar keratoderma and woolly hair (Naxos disease). Lancet 355: 2119-2124.

Merritt AJ, Berika MY, Zhai W, Kirk SE, Ji B, Hardman MJ, Garrod DR. 2002. Suprabasal desmoglein 3 expression in the epidermis of transgenic mice results in hyperproliferation and abnormal differentiation. Mol Cell Biol 22: 5846-5858.

Mertens C, Hofmann I, Wang Z, Teichmann M, Sepehri Chong S, Schnolzer M, Franke WW. 2001. Nuclear particles containing RNA polymerase III complexes associated with the junctional plaque protein plakophilin 2. Proc Natl Acad Sci 98: 7795-7800.

Mertens C, Kuhn C, Franke WW. 1996. Plakophilins 2a and 2b: Constitutive proteins of dual location in the karyoplasm and the desmosomal plaque. J Cell Biol 135: 1009-1025.

Mertens C, Kuhn C, Moll R, Schwetlick I, Franke WW. 1999. Desmosomal plakophilin 2 as a differentiation marker in normal and malignant tissues. Differentiation 64: 277-290.

Mosesson Y, Mills GB, Yarden Y. 2008. Derailed endocytosis: An emerging feature of cancer. Nat Rev Cancer 8: $835-850$.

Mueller H, Franke WW. 1983. Biochemical and immunological characterization of desmoplakins I and II, the major polypeptides of the desmosomal plaque. $J \mathrm{Mol}$ Biol 163: 647-671.

Nollet F, Kools P, van Roy F. 2000. Phylogenetic analysis of the cadherin superfamily allows identification of six major subfamilies besides several solitary members. $J$ Mol Biol 299: 551-572.

North AJ, Bardsley WG, Hyam J, Bornslaeger EA, Cordingley HC, Trinnaman B, Hatzfeld M, Green KJ, Magee AI, Garrod DR. 1999. Molecular map of the desmosomal plaque. J Cell Sci 112: 4325-4336.

Parker AE, Wheeler GN, Arnemann J, Pidsley SC, Ataliotis P, Thomas CL, Rees DA, Magee AI, Buxton RS. 1991. Desmosomal glycoproteins II and III. Cadherin-like junctional molecules generated by alternative splicing. J Biol Chem 266: 10438-10445. 
E. Delva, D.K. Tucker, and A.P. Kowalczyk

Patel HP, Diaz LA, Anhalt GJ, Labib RS, Takahashi Y. 1984. Demonstration of pemphigus antibodies on the cell surface of murine epidermal cell monolayers and their internalization. J Invest Dermatol 83: 409-415.

Payne AS, Hanakawa Y, Amagai M, Stanley JR. 2004 Desmosomes and disease: Pemphigus and bullous impetigo. Current Opinion Cell Biol 16: 536-543.

Peifer M, McCrea PD, Green KJ, Wieschaus E, Gumbiner BM. 1992. The vertebrate adhesive junction proteins beta-catenin and plakoglobin and the Drosophila segment polarity gene armadillo form a multigene family with similar properties. J Cell Biol 118: 681-691.

Pilichou K, Nava A, Basso C, Beffagna G, Bauce B, Lorenzon A, Frigo G, Vettori A, Valente M, Towbin J, et al. 2006. Mutations in desmoglein-2 gene are associated with arrhythmogenic right ventricular cardiomyopathy. Circulation 113: 1171-1179.

Pokutta S, Weis WI. 2007. Structure and mechanism of cadherins and catenins in cell-cell contacts. Ann Rev Cell Develop Biol 23: 237-261.

Prajapati V, Mydlarski PR. 2008. Advances in pemphigus therapy. Skin Ther Lett 13: 4-7.

Rickman L, Simrak D, Stevens HP, Hunt DM, King IA, Bryant SP, Eady RA, Leigh IM, Arnemann J, Magee AI, et al. 1999. N-terminal deletion in a desmosomal cadherin causes the autosomal dominant skin disease striate palmoplantar keratoderma. Human Mol Gen 8: 971-976.

Roh JY, Stanley JR. 1995. Plakoglobin binding by human Dsg3 (pemphigus vulgaris antigen) in keratinocytes requires the cadherin-like intracytoplasmic segment. $J$ Invest Dermatol 104: 720-724.

Ruiz P, Brinkmann V, Ledermann B, Behrend M, Grund C, Thalhammer C, Vogel F, Birchmeier C, Gunthert U, Franke WW, et al. 1996. Targeted mutation of plakoglobin in mice reveals essential functions of desmosomes in the embryonic heart. J Cell Biol 135: 215-225.

Sato M, Aoyama Y, Kitajima Y. 2000. Assembly pathway of desmoglein 3 to desmosomes and its perturbation by pemphigus vulgaris-IgG in cultured keratinocytes, as revealed by time-lapsed labeling immunoelectron microscopy. Lab Invest 80: 1583-1592.

Schmidt A, Heid HW, Schafer S, Nuber UA, Zimbelmann R, Franke WW. 1994. Desmosomes and cytoskeletal architecture in epithelial differentiation: Cell type-specific plaque components and intermediate filament anchorage. Eur J Cell Biol 65: 229-245.

Schmidt A, Langbein L, Pratzel S, Rode M, Rackwitz HR, Franke WW. 1999. Plakophilin 3-a novel cell-typespecific desmosomal plaque protein. Differentiation 64: 291-306.

Schmidt A, Langbein L, Rode M, Pratzel S, Zimbelmann R, Franke WW. 1997. Plakophilins 1a and 1b: Widespread nuclear proteins recruited in specific epithelial cells as desmosomal plaque components. Cell Tissue Res 290: 481-499.

Simpson MA, Mansour S, Ahnood D, Kalidas K, Patton MA, McKenna WJ, Behr ER, Crosby AH. 2008. Homozygous mutation of desmocollin-2 in arrhythmogenic right ventricular cardiomyopathy with mild palmoplantar keratoderma and woolly hair. Cardiology 113: 28-34.
Skerrow CJ, Matoltsy AG. 1974a. Chemical characterization of isolated epidermal desmosomes. J Cell Biol 63: 524-530.

Skerrow CJ, Matoltsy AG. 1974b. Isolation of epidermal desmosomes. J Cell Biol 63(2 Pt 1): 515-523.

Sklyarova T, Bonne S, D’Hooge P, Denecker G, Goossens S, De Rycke R, Borgonie G, Bosl M, van Roy F, van Hengel J. 2008. Plakophilin-3-deficient mice develop hair coat abnormalities and are prone to cutaneous inflammation. J Invest Dermatol 128: 1375-1385.

Smith EA, Fuchs E. 1998. Defining the interactions between intermediate filaments and desmosomes. J Cell Biol 141: $1229-1241$.

Sonnenberg A, Liem RK. 2007. Plakins in development and disease. Exp Cell Res 313: 2189-2203.

Stanley JR, Amagai M. 2006. Pemphigus, bullous impetigo, and the staphylococcal scalded-skin syndrome. $N$ Engl J Med 355: 1800-1810.

Steinberg MS, Shida H, Giudice GJ, Shida M, Patel NH, Blaschuk OW. 1987. On the molecular organization, diversity and functions of desmosomal proteins. Ciba Found Symp 125: 3-25.

Syed SE, Trinnaman B, Martin S, Major S, Hutchinson J, Magee AI. 2002. Molecular interactions between desmosomal cadherins. Biochem J 362: 317-327.

Troyanovsky SM, Troyanovsky RB, Eshkind LG, Leube RE, Franke WW. 1994. Identification of amino acid sequence motifs in desmocollin, a desmosomal glycoprotein, that are required for plakoglobin binding and plaque formation. Proc Natl Acad Sci 91: 10790-10794.

Tselepis C, Chidgey M, North A, Garrod D. 1998. Desmosomal adhesion inhibits invasive behavior. Proc Natl Acad Sci 95: 8064-8069.

Vasioukhin V, Bowers E, Bauer C, Degenstein L, Fuchs E. 2001. Desmoplakin is essential in epidermal sheet formation. Nat Cell Biol 3: 1076-1085.

Wahl JK 3rd. 2005. A role for plakophilin-1 in the initiation of desmosome assembly. J Cell Biochem 96: 390-403.

Wahl JK, Sacco PA, McGranahan-Sadler TM, Sauppe LM, Wheelock MJ, Johnson KR. 1996. Plakoglobin domains that define its association with the desmosomal cadherins and the classical cadherins: Identification of unique and shared domains. J Cell Sci 109: 1143-1154.

Waschke J, Bruggeman P, Baumgartner W, Zillikens D, Drenckhahn D. 2005. Pemphigus foliaceus IgG causes dissociation of desmoglein 1-containing junctions without blocking desmoglein 1 transinteraction. J Clin Invest 115: 3157-3165.

Wells WA. 2005. Defining junctional complexes. J Cell Biol 168: 989.

Whittock NV, Ashton GH, Dopping-Hepenstal PJ, Gratian MJ, Keane FM, Eady RA, McGrath JA. 1999. Striate palmoplantar keratoderma resulting from desmoplakin haploinsufficiency. J Invest Dermatol 113: 940-946.

Whittock NV, Wan H, Morley SM, Garzon MC, Kristal L, Hyde P, McLean WH, Pulkkinen L, Uitto J, Christiano AM, et al. 2002. Compound heterozygosity for non-sense and mis-sense mutations in desmoplakin underlies skin fragility/woolly hair syndrome. J Invest Dermatol 118: $232-238$. 
Williamson L, Raess NA, Caldelari R, Zakher A, de Bruin A, Posthaus H, Bolli R, Hunziker T, Suter MM, Muller EJ. 2006. Pemphigus vulgaris identifies plakoglobin as key suppressor of c-Myc in the skin. EMBO J 25: 3298-3309.

Witcher LL, Collins R, Puttagunta S, Mechanic SE, Munson M, Gumbiner B, Cowin P. 1996. Desmosomal cadherin binding domains of plakoglobin. J Biol Chem 271: 10904-10909.

Yamada S, Pokutta S, Drees F, Weis WI, Nelson WJ. 2005. Deconstructing the cadherin-catenin-actin complex. Cell 123: 889-901.

Yin T, Green KJ. 2004. Regulation of desmosome assembly and adhesion. Sem Cell Develop Biol 15: 665-677. 


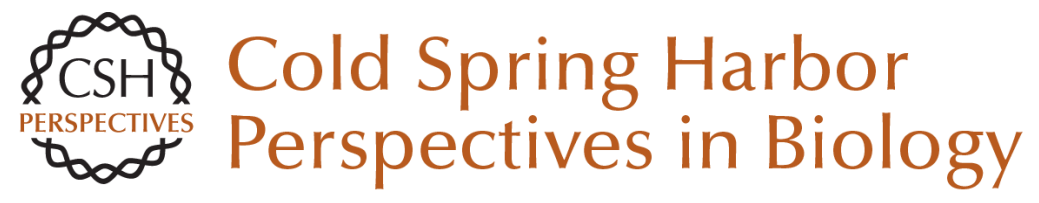

\section{The Desmosome}

Emmanuella Delva, Dana K. Tucker and Andrew P. Kowalczyk

Cold Spring Harb Perspect Biol 2009; doi: 10.1101/cshperspect.a002543

Subject Collection Cell-Cell Junctions

Vascular Endothelial (VE)-Cadherin, Endothelial

Adherens Junctions, and Vascular Disease

Maria Grazia Lampugnani, Elisabetta Dejana and

Costanza Giampietro

Adherens Junctions and Desmosomes

Coordinate Mechanics and Signaling to

Orchestrate Tissue Morphogenesis and Function:

An Evolutionary Perspective Matthias Rübsam, Joshua A. Broussard, Sara A. Wickström, et al.

Cell-Cell Contact and Receptor Tyrosine Kinase

Signaling

Christine Chiasson-MacKenzie and Andrea I. McClatchey

Hold Me, but Not Too Tight---Endothelial Cell-Cell Junctions in Angiogenesis Anna Szymborska and Holger Gerhardt

Connexins and Disease Mario Delmar, Dale W. Laird, Christian C. Naus, et al.

Cell Junctions in Hippo Signaling Ruchan Karaman and Georg Halder

Loss of E-Cadherin-Dependent Cell-Cell Adhesion and the Development and Progression of Cancer Heather C. Bruner and Patrick W.B. Derksen
Signaling by Small GTPases at Cell-Cell Junctions: Protein Interactions Building Control and Networks

Vania Braga

Making Connections: Guidance Cues and Receptors at Nonneural Cell-Cell Junctions lan V. Beamish, Lindsay Hinck and Timothy E. Kennedy

The Cadherin Superfamily in Neural Circuit Assembly James $D$. Jontes

Mechanosensing and Mechanotransduction at Cell-Cell Junctions Alpha S. Yap, Kinga Duszyc and Virgile Viasnoff

Beyond Cell-Cell Adhesion: Sensational Cadherins for Hearing and Balance Avinash Jaiganesh, Yoshie Narui, Raul Araya-Secchi, et al.

Cell-Cell Junctions Organize Structural and Signaling Networks Miguel A. Garcia, W. James Nelson and Natalie Chavez

Cell Biology of Tight Junction Barrier Regulation and Mucosal Disease Aaron Buckley and Jerrold R. Turner

For additional articles in this collection, see http://cshperspectives.cshlp.org/cgi/collection/

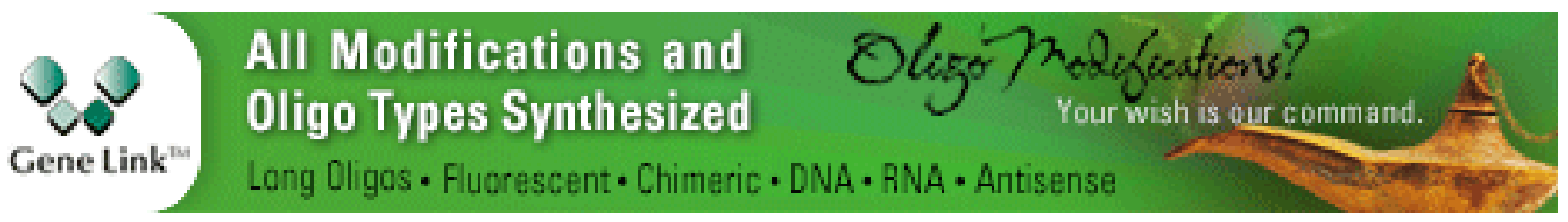


Desmosomes and Intermediate Filaments: Their Consequences for Tissue Mechanics Mechthild Hatzfeld, René Keil and Thomas M. Magin
Integration of Cadherin Adhesion and

Cytoskeleton at Adherens Junctions

René Marc Mège and Noboru Ishiyama

For additional articles in this collection, see http://cshperspectives.cshlp.org/cgi/collection/

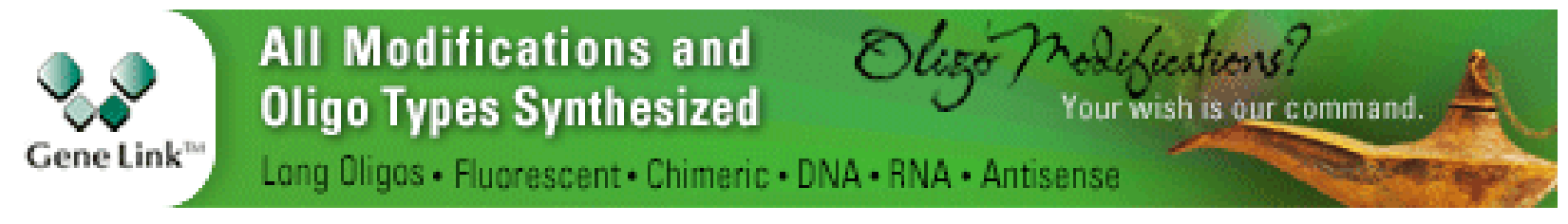

Copyright @ 2009 Cold Spring Harbor Laboratory Press; all rights reserved 